\title{
AUTOMATED CLASSIFICATION OF NATURAL FORESTS WITH LANDSAT TIME SERIES USING SIMPLIFIED SPECTRAL PATTERNS
}

\author{
Nguyen Dinh Duong \\ Institute of Geography, Vietnam Academy of Science and Technology - duong.nguyen2007@gmail.com
}

Commission III, WG III/10

KEY WORDS: Natural Forest, Landsat, Time Series, Simplified Spectral Patterns, Automated Classification

\begin{abstract}
:
Natural forests are a basic component of the earth ecology. It is essential for biodiversity, hydrological cycle regulation and environmental protection. Globally, natural forests are gradually degraded and reduced due to timber logging, conversion to cropland, production forest, commodity trees, and infrastructure development. Decreasing of natural forests results in loss of valuable habitats, land degradation, soil erosion and imbalance of water cycle in regional scale. Thus operational monitoring natural forest cover change, therefore, has been in interest of scientists for long time. Forest cover mapping methods are divided to two groups: field-based survey and remotely sensed image data based techniques. The field-based methods are conventional and they have been used widely in forestry management practice. Satellite-image-based methods were developed since beginning of earth observation. These methods, except visual image interpretation, can be grouped to supervised and unsupervised classification that rely on various algorithm as statistical, clustering or artificial intelligence. However, there is little report about method, which can extract natural forests from generic forest cover. Over the last couple of decades, natural forests have been over-exploited by various reasons. This practice led to urgent need of development of fast, reliable and automated method for mapping natural forests. In this study, a new method for mapping of natural forest by Landsat time series is presented. The new method is fully automated. It uses spectral patterns as principal classifier to recognize land cover classes. The proposed method was applied in study area consisted of Ratanakiri of Cambodia, Attapeu of Laos and Kon Tum of Vietnam. About 2000 Landsat images were used to generate land cover maps of the study area across years from 1989 to 2018.
\end{abstract}

\section{INTRODUCTION}

Natural forest is important for biodiversity and environmental protection as well as for socio-economy and the living conditions of forest-dependent populations (Stibig et al., 2014). Globally, natural forests are gradually degraded and reduced due to timber logging, conversion to cropland, production forest, commodity trees, and infrastructure development. Decreasing of natural forests results in loss of valuable habitats, land degradation, soil erosion and imbalance of water cycle in regional scale (Dennis et al., 2008). Thus operational monitoring natural forest cover change, therefore, has been in interest of scientists for long time. Methods for monitoring forest cover using Landsat time series (LTS) have been extensively studied during the last two decades. In general, application of LTS for forest mapping can be categorized into two types: image classification and trajectorybased analysis (Banskota et al., 2014). In image classificationbased analysis, individual images are separately classified, thereby minimizing the problem of radiometric calibration between dates (Coppin and Bauer, 1996). Trajectory based approaches utilize the temporal patterns of spectral variables to detect disturbance types and magnitude. Unlike classification, it involves analysis of a time series of single spectral variables and can be further divided into 4 categories: (i) threshold-based change detection, (ii) single curve fitting, (iii) hypothesized curve fitting, and (iv) trajectory segmentation (Banskota et al., 2014).

Analysis of LTS requires careful image selection and preprocessing. Images of LTS are selected according to image quality and acquisition dates. The rules for selecting the best available pixel observation can be related to nearness to a target day of year and avoidance of atmospheric interference (be it cloud, haze or resultant shadows), or prioritization of a particular sensor (White et al., 2014).

Radiometric correction and atmospheric correction also play important roles in LTS preparation. Radiometric correction includes calibration to radiance or at-satellite reflectance, while atmospheric correction is performed to achieve minimal radiometric differences between images observed in different time.

In this study, a new method for mapping of natural forest by LTS is presented. Landsat image data covering provinces Ratanakiri of Cambodia, Attapeu of Laos and Kon Tum of Vietnam since 1989 to 2018 were used to map natural forest cover. Natural forest is assumed as forest cover, which is not disturbed during the course of 30 years. More than 2000 Landsat scenes of sensors $\mathrm{TM}, \mathrm{ETM}+$ and OLI were used for testing the proposed algorithm. Automated classification was conducted with base land cover categories: Cloud, cloud shadow, water, wetland, closed forest, open forest, and area of intense human activities. The study showed that the proposed method for mapping natural forest is stable, independent and uniform for natural forest inventory in large areas. The advantage of the newly proposed method is that it provides not only statistic data, but also spatiotemporal patterns on how the natural forest was reduced across time.

\section{MATERIALS AND METHODS}

\subsection{Study Area}

The study area is composed of three neighbouring provinces: Ratanakiri of Cambodia, Attapeu of Laos and Kon Tum of Vietnam. These provinces situate in western site of the Truong Son range so they are of very similar climate characteristics (Fig. 
1). In the study area, there are two distinct seasons: dry and rainy. The rainy season starts in May and ends in October. The dry season lasts from November to April annually. Due to influences of monsoon climate there is low opportunity to obtain cloud free image, especially during rainy season. Prevalent vegetation cover of the study area is evergreen. However, there are also deciduous broad-leaved forests that lose their leaves during dry season.

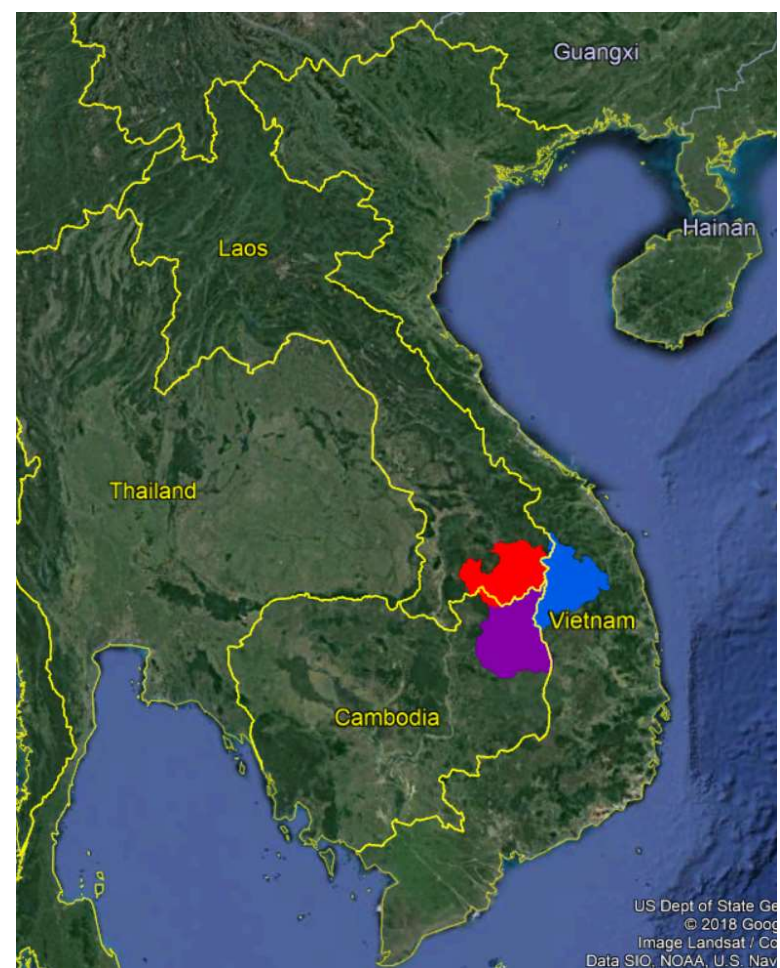

Figure 1. Study area with three provinces of Cambodia, Laos and Vietnam. Ratanakiri is coloured in violet, Attapeu in red and Kon Tum in blue.

\subsection{Landsat Time Series}

2.2.1 Landsat Collection 1 Level-1

LTS are composed of Landsat Collection 1 Level-1 data. Precision (ground control) and terrain corrected products are labelled with the L1TP designation. Terrain and systematic corrected products are labelled as L1GT. Systematically corrected products are labelled as L1 GS. OLI / TIRS products are either L1TP or L1GT and ETM+, TM, and MSS products are L1TP, L1GT, or L1 GS. Radiometric and geometric data quality characteristics are available in sensor-, scene-, and pixel-level metadata (USGS, 2019a). The Landsat Collection 1 Level-1 is available on website https://earthexplorer.usgs.gov/ for downloading.

\subsubsection{Image Selection}

Forest types in the study area are of two types: evergreen and deciduous broad leaf. Evergreen forest has stable leaf coverage around the year while deciduous broad leaf forest loses leaves during dry season. Forest with no leaves causes miss classification so only images beside the dry season are selected for research. Images of months from May to December for the period from 1989 to 2018 were downloaded from the website https://earthexplorer.usgs.gov/. The study area is covered by five scenes with path/row numbers $124 / 49,124 / 50,124 / 51,125 / 50$ and $125 / 51$. Total number of images used for research was about 2000.

\subsubsection{Computation of Top of Atmosphere Reflectance}

Before analysis, digital numbers (DN) of pixels were converted to top of atmosphere (TOA) reflectance to minimize image-toimage variability. There are three advantages of using TOA reflectance instead of at-sensor spectral radiance. First, it removes the cosine effect of different solar zenith angles due to the time difference between data acquisitions. Second, TOA reflectance compensates for different values of the exoatmospheric solar irradiance arising from spectral band differences. Third, the TOA reflectance corrects for the variation in the Earth-Sun distance between different data acquisition dates. These variations can be significant geographically and temporally. The TOA reflectance of the Earth is computed according to the equation:

$$
\rho_{\lambda}=\frac{\pi \cdot L_{\lambda} \cdot d^{2}}{E S U N_{\lambda} \cdot \cos \theta_{s}}
$$

\begin{tabular}{|c|c|}
\hline Where & \\
\hline$\rho_{\lambda}=$ & Planetary TOA reflectance [unitless] \\
\hline$\pi=$ & $\begin{array}{l}\text { Mathematical constant equal to } \\
\sim 3.14159 \text { [unitless] }\end{array}$ \\
\hline$L_{\lambda}=$ & $\begin{array}{l}\text { Spectral radiance at the sensor's aperture } \\
{[\mathrm{W} /(\mathrm{m} 2 \mathrm{sr} \mu \mathrm{m})]}\end{array}$ \\
\hline$d=$ & Earth-Sun distance [astronomical units] \\
\hline $\operatorname{ESUN}_{\lambda}=$ & $\begin{array}{l}\text { Mean exoatmospheric solar irradiance } \\
{[\mathrm{W} /(\mathrm{m} 2 \mu \mathrm{m})]}\end{array}$ \\
\hline$\theta_{s}=$ & Solar zenith angle [degrees] \\
\hline
\end{tabular}

Conversion of DN to TOA reflectance was carried out differently for sensors TM, ETM+ (Chander et al., 2009) and OLI.

For OLI sensor, conversion of Level $1 \mathrm{DN}$ to TOA reflectance is done by equation 2 (USGS, 2019b).
Where$$
\rho_{\lambda}^{\prime}=M_{\rho} \cdot Q_{c a l}+A_{\rho}
$$
$\rho_{\lambda}^{\prime}=\quad$ TOA Planetary Spectral Reflectance, without
correction for solar angle. (unitless)
$M_{\rho}=\quad$ Reflectance multiplicative scaling factor for the band. (REFLECTANCEW_MULT_BAND_n from the metadata).
$A_{\rho}=\quad$ Reflectance additive scaling factor for the band (REFLECTANCE_ADD_BAND_N from the metadata).
$Q_{c a l}=\quad$ Level 1 pixel value in DN

The $\rho_{\lambda}^{\prime}$ is not true TOA Reflectance, because it does not contain a correction for the solar elevation angle. This correction factor is left out of the Level 1 scaling at the users' request; some users are content with the scene-center solar elevation angle in the metadata, while others prefer to calculate their own per-pixel solar elevation angle across the entire scene. Once a solar elevation angle is chosen, the conversion to true TOA reflectance is as follows:

$$
\rho_{\lambda}=\frac{\rho_{\lambda}^{\prime}}{\cos \theta_{s z}}=\frac{\rho_{\lambda}^{\prime}}{\sin \theta_{s e}}
$$

Where

$\rho_{\lambda}=\quad$ Planetary TOA reflectance [unitless]

$\theta_{S z}=\quad$ Local sun elevation angle; the scene center sun elevation angle in degrees is provided in the metadata.

$\theta_{s e}=\quad$ Local solar zenith angle; $\theta_{s z}=90^{\circ}-\theta_{s e}$

\subsubsection{Cloud Masking}

Cloud masking is done by using Landsat Collection 1 Level-1 quality assessment band (QA). The Landsat Collection 1 Level- 
1 Quality Assessment (QA) 16-bit band allows users to apply per pixel filters to all Landsat Collection 1 Level-1 data products. Each pixel in the QA band contains unsigned integers that represent bit-packed combinations of surface, atmospheric, and sensor conditions that can affect the overall usefulness of a given pixel. Landsat Collection 1 Level-1 QA bands (.TIF) are included in the Landsat Level-1 GeoTIFF Data Product downloaded from EarthExplorer (USGS, 2017). The QA band provides useful information on cloud, cloud confidence and cloud shadow confidence. The confidence levels of cloud and cloud shadow are divided to three levels: low, medium and high equivalent to $0 \%$ $33 \%, 34 \%-46 \%$ and $67 \%-100 \%$ respectively.

\subsection{Methods}

The goal of our proposed procedure for natural forest mapping is to detect contiguous forest, which is undisturbed during period from 1989 to 2018. We consider long-time undisturbed forest as natural one. This concept requires classification of study area to at least two classes: natural forest and non-natural forest areas. The procedure, therefore, is broken down to two major steps: classification of land cover and accumulation of bare land areas across time. We assume that natural forest changes are caused by human activities in form of timber logging or conversion to agricultural or developed land. Selective timber logging converts closed to open forest while clear cutting or conversion of forest land to other land use forms always experiencing a period when forest land changed to bare land. Hence, detection of bare land is one of steps for classification of non-natural forest areas.

\subsubsection{Simplified Spectral Patterns}

The simplified spectral pattern (SSP) concept has been used for automated classification of land cover and water body extraction with Landsat images (Duong, 2018, 2016, 2012; Duong et al., 2017). An SSP is a transformation of the full spectral pattern into a simplified digital form, which allows direct incorporation of the spectral pattern into the classification. The SSP is constructed by non-repetitive pairwise comparison of reflectance values between two bands (Charalambides, 2002). Given a pixel value vector $\mathrm{B}_{6}=\left\{\mathrm{b}_{1}, \mathrm{~b}_{2}, \mathrm{~b}_{3}, \mathrm{~b}_{4}, \mathrm{~b}_{5}, \mathrm{~b}_{6}\right\}$, where $\mathrm{b}_{1}, \mathrm{~b}_{2}, \ldots, \mathrm{b}_{6}$ denote top of atmosphere (TOA) reflectance of bands $2,3,4,5,6$, and 7 of OLI, and bands $1,2,3,4,5$, and 7 of ETM+ sensor, respectively, the simplified spectral pattern is defined by a new 15 digit vector, shown in equation (1).

$$
m_{1,2} m_{1,3} m_{1,4} m_{1,5} m_{1,6} m_{2,3} m_{2,4} m_{2,5} m_{2,6} m_{3,4}
$$

$m_{3,5} m_{3,6} m_{4,5} m_{4,6} m_{5,6}$

where $m_{i, j}$ is the result of comparison between the reflectance of $b_{i}$ and $b_{j}$ and has values of 0 (if $b_{j}<b_{i}$ ), 1 (if $\left.b_{j}=b_{i}\right)$, or $2\left(b_{j}>b_{i}\right)$. An example of SSP construction is presented in Fig. 2.

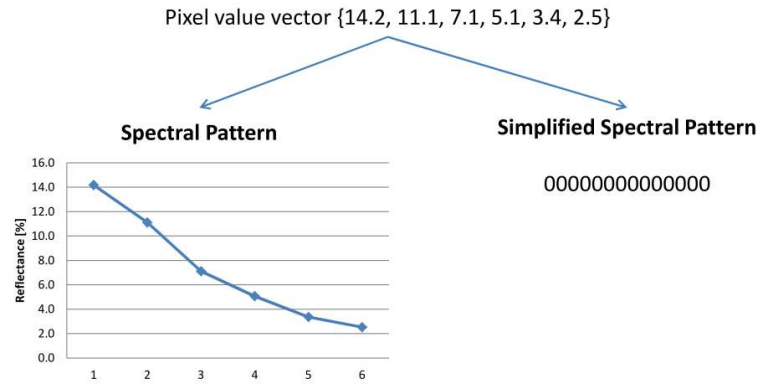

Figure 2. Example of a transformation of the spectral pattern into a simplified spectral pattern.
2.3.2 Development of Simplified Spectral Pattern Database of Major Land Cover Classes

To facilitate automation of classification of land cover, we need to develop a database of major land cover classes. Due to slight differences of spectral characteristics of sensors TM, ETM+ and OLI we have to develop different databases of SSP for major land cover categories for each sensors. These databases are used for classification of single date Landsat images. The following categories are included in the databases: cloud, cloud shadow, water, wetland, mangrove, and green vegetation, and brown vegetation, deciduous woodland and dry bare land. Due to complexity of land cover characteristics, each land cover class involves one or more SSPs. Identification of SSP for each land cover class was realized by visual interpretation. A special software tool was developed for this purpose. The database of SSPs for TM sensor contains 45 SSPs. For ETM+ there are 46 SSPs in the database and for OLI, the database has 43 SSPs in total. Table 1 shows examples of SSPs for three land cover classes dark green vegetation, bright green vegetation and dry bare land for all three Landsat sensors.

\begin{tabular}{|l|lll|}
\hline $\begin{array}{l}\text { Land } \\
\text { cover } \\
\text { class }\end{array}$ & \multicolumn{3}{|c|}{ Simplified Spectral Pattern } \\
\hline DGV sensor & ETM+ sensor & OLI sensor \\
\hline DGV & 002200220220000 & 002200220220000 & 002200220222000 \\
& 002000220220000 & & \\
& 002200220220000 & 002200220220000 & 002200220222000 \\
& 002200220222000 & 002200220222000 & 002200222222000 \\
& 002220222222000 & 002200222222200 & 022222222222000 \\
& 202220220222000 & 202200220222000 & 202220222222000 \\
& 202220222222000 & 222200220220000 & 202200220222000 \\
& & 202200220220000 & 202200220220000 \\
& 002222222222200 & 002220222222200 & 022222222222200 \\
& 002220222222200 & 002222222222200 & 022222222222200 \\
& 022222222222200 & 022222222222200 & 002222222222200 \\
& 222222222222200 & 22222222222200 & 002222222222200 \\
& 022222222222000 & 022222222222000 & 022222222222220 \\
& 002200222222200 & 002202222222000 & 222222222222220 \\
& 222222222222000 & 222222222222000 & 222222222222200 \\
& 000220222222222 & 022222222222220 & 002222222222220 \\
& 002222222222220 & 002222222222220 & 002200222222200 \\
& 222222222222220 & 22222022222200 & 222222222220200 \\
& 222222222220200 & 222222222222220 & 002220222222220 \\
& & 222220222222000 & \\
& & 222222222220200 & \\
\hline
\end{tabular}

Table 1. Examples of SSPs for three land cover classes DGVdark green vegetation, $\mathrm{BGV}$-bright green vegetation and DBL-dry bare land.

In our method, every land cover class is recognized primarily by an SSP. However, to identify more specifically a particular class of land cover we need to use some supporting variables that are computed using TOA reflectance. There are seven variables, which help us to better describe a shape of a spectral pattern. List of those variables are given in Table 2 .

\begin{tabular}{|c|l|}
\hline Variables & \multicolumn{1}{|c|}{ Formula } \\
\hline $\mathrm{T}_{1}$ & $\left(\mathrm{~B}_{1}+2 * \mathrm{~B}_{2}+\mathrm{B}_{3}\right) / 2$ \\
\hline $\mathrm{T}_{2}$ & $\left(\mathrm{~B}_{4}+2 * \mathrm{~B}_{5}+\mathrm{B}_{6}\right) / 2$ \\
\hline $\mathrm{R}_{1}$ & $\mathrm{~B}_{5} / \mathrm{B}_{4}$ \\
\hline $\mathrm{R}_{2}$ & $2 * \mathrm{~B}_{5} /\left(\mathrm{B}_{4}+\mathrm{B}_{6}\right)$ \\
\hline $\mathrm{R}_{3}$ & $\mathrm{~B}_{5} / \mathrm{B}_{3}$ \\
\hline $\mathrm{R}_{4}$ & $\mathrm{~B}_{5} / \mathrm{B}_{2}$ \\
\hline $\mathrm{R}_{5}$ & $\mathrm{~B}_{4} / \mathrm{B}_{5}$ \\
\hline
\end{tabular}

Figure 3. List of variables that support better description of a shape of a spectral pattern. $\mathrm{B}_{1}$--- $\mathrm{B}_{3}$ denote TOA reflectance for bands blue, green, red, near infrared, short infrared land shortwave infrared 2 respectively. 
Number of supporting variables needed for identification of a land cover class is not fixed for all classes. Some classes such as clear water does not need any supporting variables. Some other classes with high probability of mixture with other classes such as wetland or dry bare land require always supporting variables. The database of SSPs therefore contains both SSPs and supporting variables for every land cover classes. Example of using a software tool to identify SSP and supporting variables for a pixel in a image is given in figure 4.

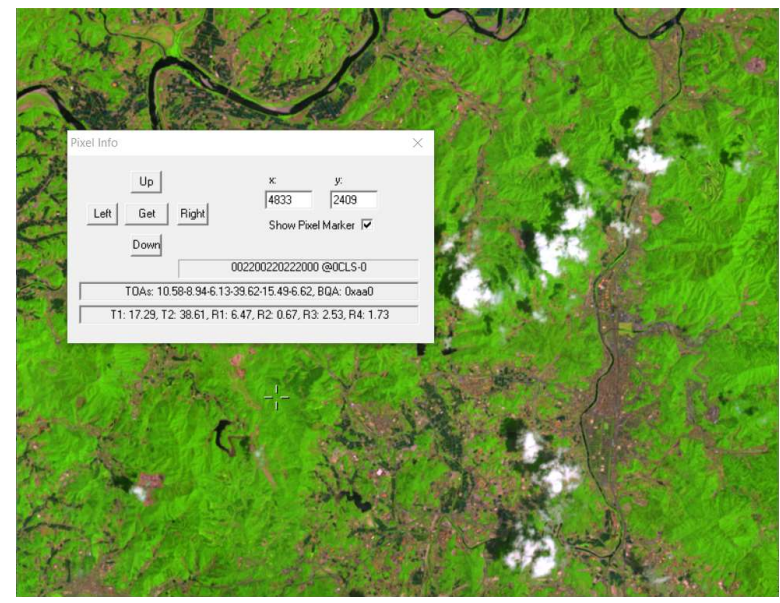

Figure 4. Example of using a software tool to identify SSP and supporting variables. The Pixel info windows shows SSP code, number of SSP codes available within the image, pixel vector in TOA reflectance and values of seven supporting variables.

2.3.3 Automated Classification of Land Cover

Algorithm for the automated classification of land cover is straightforward. Figure 4 shows major steps for the classification of land cover using the database of SSPs. The algorithm is a simple loop of two computation steps: conversion of pixel value vectors to TOA reflectance and comparison of SSPs and supporting variables of a pixel with SSPs and supporting variables. Computation of TOA reflectance is conducted differently for Landsat sensors using information provided in the metadata files. The complexity of spectral characteristics of surface materials results pixels with SSPs not yet defined in the databases. These pixels are classified to unknown class as usual in practice of image classification. If the number of unknown pixels is too large and those pixels threaten quality of classification result, we need to identify new SSP and to update the database of SSP to reduce unknown pixels in classification result. If there is still small number of unknown pixels after classification, spectral matching could be applied to fill those unknown pixels.

2.3.4 Stacks of Images within one year

Landsat images of tropical region are always disturbed by clouds. It is inevitable facts. Clouds and cloud shadows are required to be reliably identified if we need to achieve good result of classification of land cover with Landsat time series. To reach cloud free land cover map in certain time period (dry or wet season) we need to classify more Landsat images and stack them together. Information on clouds and cloud shadows can be extracted from band quality assessment (BQA) that associates with every Landsat image in Landsat collection 1 (USGS, 2019a, 2017). By using the BQA we can identify cloud and cloud shadow pixels in one image and replace them by clear pixels from images of other date in Landsat time series. Figure 5 demonstrates stacking of classified images to create cloud free classified images.

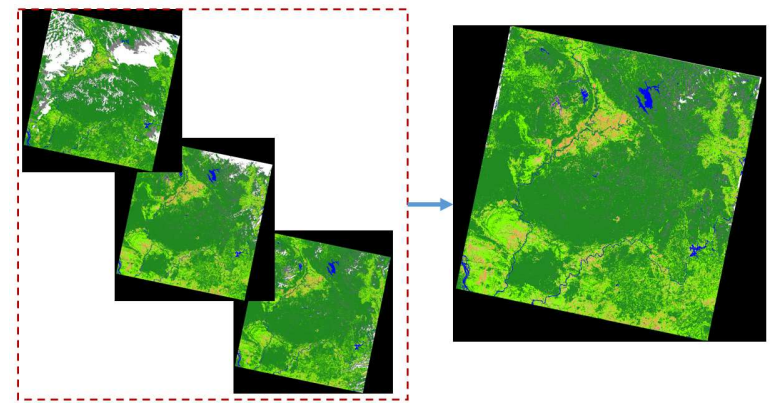

Figure 5. To demonstrate image stacking to create cloud free classified image. Single date classified images are in left side block. After stacking, cloud free image is created and shown in right side.

2.3.5 Natural Forests Extraction

We assume that natural forest is a forest that is not substantially changed during its existence except consequence of hazard like landslides or fire. This assumption redirects detection of natural forest to detection of change of forest to bare land during its existence. In the study area, two prevalent forest covers evergreen and dry deciduous forest. Dry deciduous forest has leaf-off season from late December to April of the next year. During this period, dry deciduous forest looks like bare land on Landsat image. To avoid miss classification we do not collect Landsat image of area with distribution of dry deciduous forest. We accumulate classified images of one year to find changed and unchanged forest covers. When we stack multiple-year classified images, again, we can mark changed and unchanged forest covers. The long-time unchanged forest cover is then classified to natural forest cover. Figure 6. Displays flow chart of algorithm for automated classification of land cover and natural forest mapping.
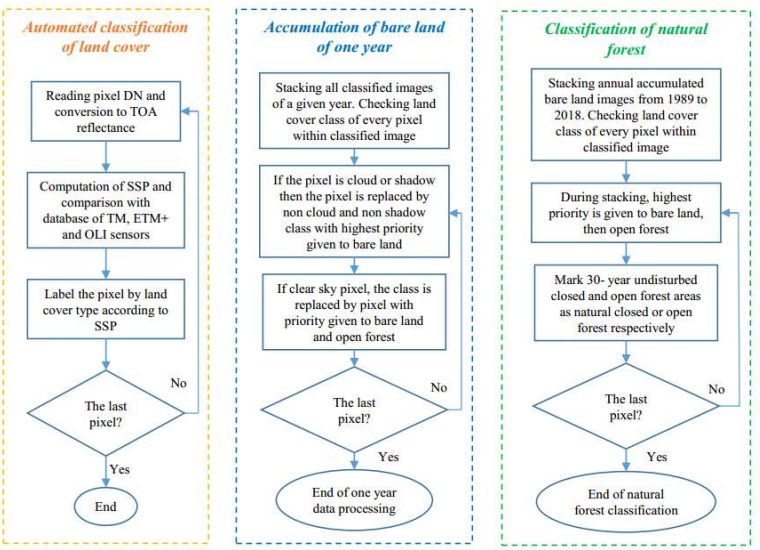

Figure 6. Flow chart of algorithm for automated classification of land cover and natural forest mapping.

\section{RESULTS AND DISCUSSION}

Algorithm described in the methods session was implement using $\mathrm{C}++$ language for application in Windows 32-bit and 64-bit environment. The software running in command mode allows batch processing of large amount of Landsat images. All Landsat Collection 1 level-1 images of the study area since 1989 to 2018 were selected for classification. About 2000 images were analysed, stacked and subset and mosaicked according to the boundaries of provinces. For each province, we created annual land cover map with four classes: closed natural forest CNF, open natural forest ONF, water and area of intense human activities 
IHA. The class IHA includes forest plantation, industrial trees, crop and paddy fields, and human settlements. A set of 30 annual land cover maps provides spatio-temporal changes of the three classes CNF, ONF and IHA from 1989 to 2018 in the study area. Quantitative analysis of changes of natural forest reveals trends of land use in Cambodia, Laos and Vietnam in the past 30 years. 3.1.1 Ratanakiri Province

Natural closed forest in Ratanakiri was reduced from from 958,575 ha in 1989 to 466,529 ha in 2018 equivalent to loss of $51.3 \%$ (annual $1.7 \%$ ). Closed natural forest was replaced by open natural forest and area of intense human activities. Open natural forest was increased from 277,796 ha in 1989 to 530,814 ha in 2018 , equivalent to gain of $91.1 \%$ while area of intense human activities increased from 31,495 ha in 1989 to 273,830 ha in 2018 , equivalent to gain of $769.4 \%$. Figure 7 shows changes of natural forest of Ratanakiri from 1989 to 2018 .

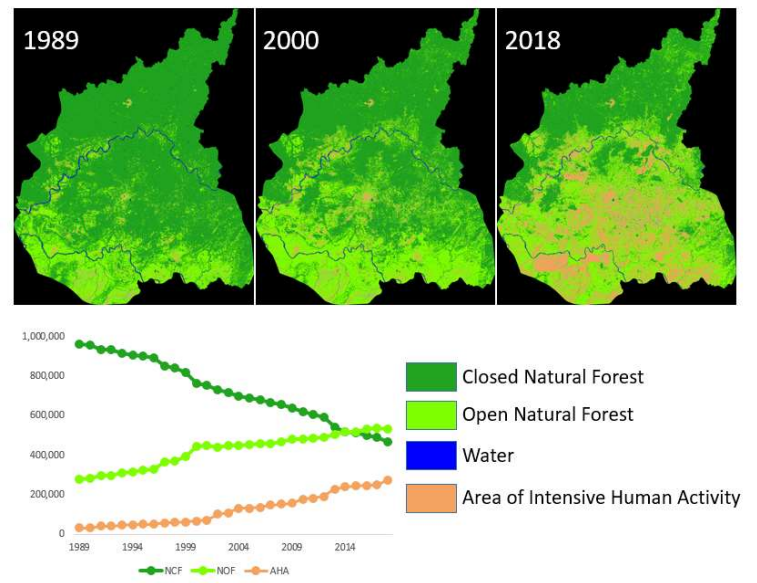

Figure 7. 30-year change of natural forests in Ratanakiri province of Cambodia. Three classified images in upper part of the figure show land cover maps in years 1989, 2000 and 2018. Graph in lower part visualizes quantitative changes closed and open natural forest and area of intense human activities.

3.1.2 Attapeu Province

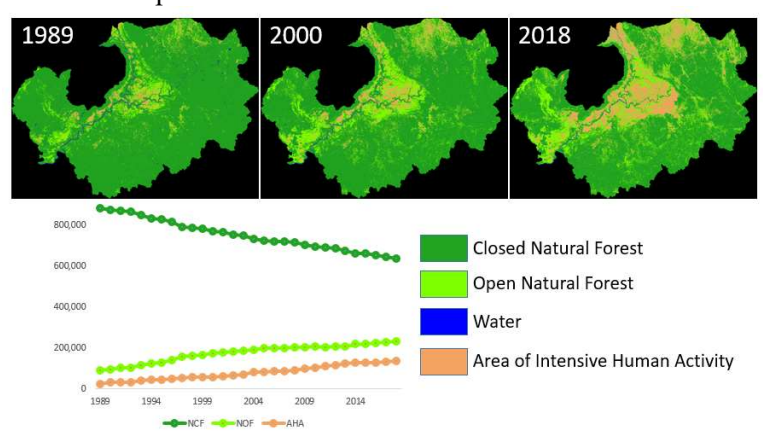

Figure 8. 30-year change of natural forests of Attapeu province of Laos. Three classified images in upper part of the figure show land cover maps in years 1989, 2000 and 2018. Graph in lower part visualizes quantitative changes closed and open natural forest and area of intense human activities.

Natural closed forest in Attapeu was decreased from 879,005 ha in 1989 to 634,557 ha in 2018 , equivalent to loss of $27.8 \%$ (annual $0.93 \%$ ). Natural open forest was extended from 90,752 ha in 1989 to 231,830 ha in 2018 equivalent to gain of $155.4 \%$. Area under intensive human activities increased from 23,957 ha in 1989 to 138,675 ha in 2018 , equivalent to gain of $478.8 \%$.
Figure 8 presents analysis results of land cover changes for Attapeu province.

3.1.3 Kon Tum Province

Natural closed forest in Kon Tum was reduced from 848,307 ha in 1989 to 424,388 ha in 2018 equivalent to loss of $50 \%$ (annual $1.7 \%$ ). Natural open forest was enlarged from 78,629 ha in 1989 to 224,963 ha in 2018 , equivalent to gain of $186.1 \%$. Area under intensive human activities increased from 40,098 ha in 1989 to 320,354 ha in 2018 , equivalent to gain of $698.9 \%$. Figure 9 displays 30 -year changes of natural closed and open forest of Kon Tum province.

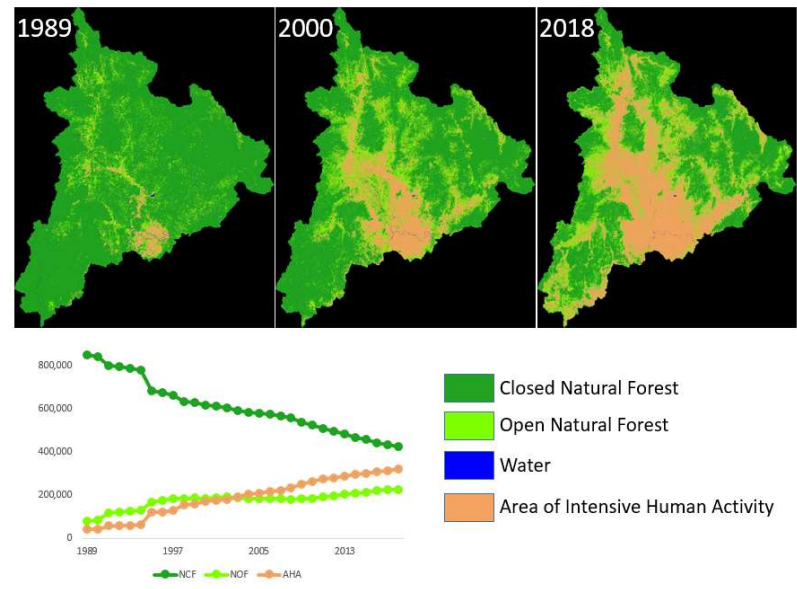

Figure 9. 30-year change of natural forests of Kon Tum province of Vietnam. Three classified images in upper part of the figure show land cover maps in years 1989, 2000 and 2018. Graph in lower part visualizes quantitative changes closed and open natural forest and area of intense human activities.

\subsubsection{Validation}

The validation of classification results was possible only for year 2018. It is quite hard to validate reliability of classification for past years. We conducted field survey in December 2018 and March 2020 to collect ground data for classification accuracy analysis. For inaccessible area, high spatial resolution imagery of Google Earth was used for validation. Because spectral pattern was used as main classification measure in our proposed method so validation of classification results is equal to validation of spectral patterns and their simplified forms. Field survey in 2018 and the use of high spatial resolution of Google Earth showed very high accuracy of 2018 land cover maps. We assume that spectral patterns of ground materials observed by Landsat sensors are stable across time so we are of high confidence that classification results of Landsat images in the past years have high reliability.

\section{CONCLUSION}

In this paper, we introduced a new algorithm for automated classification of land cover with Landsat time series. Forest cover that remain unchanged during long period is considered as natural forest. The algorithm is composed of three processing steps. In the first step, Landsat image is automatically classified by using database of simplified spectral patterns developed for individual Landsat sensors. In the second step, single date classified land cover maps are stacked to create annual cloud free land cover maps. In the third step, by stacking all annual land cover maps we will extract natural forest and area of intense human activities. For each provinces in the study area, we generated series of land cover maps showing spatio-temporal changes of land cover across 30 years. Classification results 
reveal both qualitative and quantitative dynamics of land cover changes in the study area.

\section{ACKNOWLEDGEMENTS}

The author gratefully acknowledges financial support by grant number TN18/ T09 under the research program KHCN-TN/1620 from the Vietnam Academy of Science and Technology.

\section{REFERENCES}

Banskota, A., Kayastha, N., Falkowski, M.J., Wulder, M.A., Froese, R.E., White, J.C., Banskota, A., Kayastha, N., Falkowski, M.J., Michael, A., Froese, R.E., White, J.C., Monitoring, F., Landsat, U., Banskota, A., Kayastha, N., Falkowski, M.J., Michael, A., Froese, R.E., White, J.C., Forest, C., Pacific, S., Centre, F., Canada, N.R., 2014. Forest Monitoring Using Landsat Time Series Data: A Review Forest Monitoring Using Landsat Time Series Data: A Review 8992, 362-384. https://doi.org/10.1080/07038992.2014.987376

Chander, G., Markham, B.L., Helder, D.L., Ali, E.-, 2009. Remote Sensing of Environment Summary of current radiometric calibration coef fi cients for Landsat MSS , TM , ETM + , and EO-1 ALI sensors. Remote Sensing of Environment 113, 893-903. https://doi.org/10.1016/j.rse.2009.01.007

Charalambides, C.A., 2002. Enumerative Combinatorics, in: Enumerative Combinatorics. pp. 40-42.

Coppin, P.R., Bauer, M.E., 1996. Digital change detection in forest ecosystems with remote sensing imagery Digital Change Detection in Forest Ecosystems with Remote Sensing Imagery. Remote sensing reviews 13, 207-2341. https://doi.org/10.1080/02757259609532305

Dennis, R.A., Meijaard, E., Nasi, R., Gustafsson, L., 2008. Biodiversity Conservation in Southeast Asian Timber Concessions : a Critical Evaluation of Policy Mechanisms and Guidelines. Ecology and Society 13.

Duong, N.D., 2018. Decomposition of Landsat 8 OLI Images by Simplified Spectral Patterns for Land Cover Mapping. 2018 10th IAPR Workshop on Pattern Recognition in Remote Sensing (PRRS) 1-13.

Duong, N.D., 2016. Automated classification of Land cover using Landsat 8 OLI Surface Reflectance product and spectral pattern analysis concept - Case study in Hanoi, Vietnam. International Archives of the Photogrammetry, Remote Sensing and Spatial Information Sciences - ISPRS Archives 41, 987-991. https://doi.org/10.5194/isprsarchives-XLI-B8-987-2016

Duong, N.D., 2012. Water body extraction from multi spectral image by spectral pattern analysis, in: International Archives of the Photogrammetry, Remote Sensing and Spatial Information Sciences - ISPRS Archives. pp. 181186.

Duong, N.D., Hang, L.M., Tuan, T.A., Ouyang, Z., 2017. Development of a spectral-pattern-analysis-based method for automated water body extraction using Landsat image data: A case study in central Vietnam and southern Laos. Limnology and Oceanography: Methods 15, 945-959. https://doi.org/10.1002/lom3.10215

Stibig, H., Achard, F., Carboni, S., Raši, R., Miettinen, J., 2014. Change in tropical forest cover of Southeast Asia from 1990 to 2010. EGU General Assembly Conference Abstracts 20, 247-258. https://doi.org/10.5194/bg-11247-2014

USGS, 2019a. LANDSAT COLLECTION 1 LEVEL 1
PRODUCT DEFINITION Version 2.0

USGS, 2019b. Landsat 8 ( L8 ) Data Users Handbook. Book 8. USGS, 2017. USER GUIDE LANDSAT QUALITY ASSESSMENT (QA) TOOLS.

White, C.J., Wulder, M.A., Hobart, G.W., Luther, J.E., Hermosilla, T., Griffiths, P., Guindon, L., 2014. PixelBased Image Compositing for Large-Area Dense Time Series Applications and Science Pixel-Based Image Compositing for Large-Area Dense. Canadian Journal of Remote Sensing 40, 192-212. https://doi.org/10.1080/07038992.2014.945827 